\title{
Tuberculosis as a co-morbidity finding in medicolegal autopsies
}

\author{
Dina Mary .M', Arasi Rajesh ${ }^{2, *}$, Suresh Durai J ${ }^{3}$ \\ ${ }^{\mathbf{1}}$ Assistant Professor, ${ }^{2,3}$ Professor, Dept. of Pathology, Tirunelveli Medical College, Tamil Nadu, India
}

*Corresponding Author:

Email: arasirajesh@yahoo.co.in

Received: $20^{\text {th }}$ March, 2018

Accepted: $4^{\text {th }}$ April, 2018

\begin{abstract}
India is the most tuberculosis prevalent country in the world. Many cases of active tuberculosis are diagnosed at autopsy. This study was aimed to determine the autopsy prevalence of tuberculosis over a period of 3 years at a tertiary care centre. Out of 801 cases of autopies done in 3 years, 27 cases (3.37\%) had tuberculosis and 92.59\% of cases were active tuberculosis. Most of the cases were seen in men of 40-50 years age group. There is an increasing trend in number of cases over the years. Autopsy cases of tuberculosis can be a source of transmission to health care providers in autopsy rooms and in pathology department. Complex clinical histories prevent the clinical diagnosis of tuberculosis, so clinicians should be sensitised and stringent screening for tuberculosis should be done in all patients with respiratory symptoms.
\end{abstract}

Keywords: Tuberculosis, Autopsy, Active tuberculosis.

\section{Introduction}

Tuberculosis is a major health concern in India as it contributes to nearly $25 \%$ of the global disease burden. There has been a global increase in notification of new cases to which India has contributed the most (ie) nearly 35\% increase from 2013 to $2016 .{ }^{1}$ Further India has more than a million hidden cases every year due to diverse symptomatology, inaccurate diagnostics and precocious death. This study was done to know the prevalence of tuberculosis in autopsy cases with the aid of gross and histomorphological features.

\section{Materials and Methods}

This study includes all forensic autopsies that were received in Department of pathology, Tirunelveli Medical College over a period of three years between January 2014 and December 2017 where a nontuberculous etiology was found to be the cause of death. A detailed gross examination of all organs were retrieved from the records. The blocks were retrieved and representative sections stained with $\mathrm{H} \& \mathrm{E}$ were examined under microscope. Active tuberculosis was diagnosed based on the presence of epithelioid granulomas with caseation necrosis, with or without Langhans giant cells. The lesion was either confined to one organ or involved multiple organs when it was considered miliary. The inactive lesions of lung have minimal inflammation, extensive fibrosis with fibrous encapsulation and may have dystrophic calcification. ${ }^{2}$

\section{Results}

A total of 801 autopsies were done over 3 years. There were 629 males and 172 females.23 out of 629 males and 4 out of 172 females showed tuberculous lesions. Out of a total of 801 cases, 27(3.37\%) cases showed presence of tuberculous lesions. The highest number of cases were seen in men (85.18\%).Most of these men were in the age group of 40-50 years in our study (Table 1). The lungs were involved in all the cases $(100 \%)$. In addition spleen was involved in 2 out of 27 cases and spleen with liver together were involved in 3 out of 27 cases. We found disseminated tuberculosis in 5 cases $(18.5 \%)$. All the 5 cases of disseminated tuberculosis were seen in the last year of study i.e. 2017.

Pulmonary lesions with caseation and epithelioid granulomas were seen in 14 cases and granulomas without caseation was seen in 10 cases, one case had tuberculous pneumonia. 2 cases had regressing tuberculous lesion with fibrosis. Active tuberculosis was seen in 25 out of 27 cases $(92.6 \%)$ and the remaining 2 had inactive lesions $(7.4 \%)$. Out of the 25 cases with active lesions, in 2 cases, tuberculosis was found to be the cause of death and not a co-morbid finding. The occurrence of $\mathrm{Tb}$ over 3 years shows an increasing trend (Table 2).

\section{Table 1: Age and sex distribution of tuberculous} cases

\begin{tabular}{|l|c|c|c|c|}
\hline \multirow{2}{*}{$\begin{array}{c}\text { Age in } \\
\text { years }\end{array}$} & \multicolumn{2}{|c|}{ Male } & \multicolumn{2}{c|}{ Female } \\
\cline { 2 - 5 } & No & \% & No & \% \\
\hline $0-10$ & - & - & - & - \\
\hline $10-20$ & 1 & 3.7 & 3 & 11.1 \\
\hline $20-30$ & - & - & 1 & 3.7 \\
\hline $30-40$ & 4 & 14.8 & - & - \\
\hline $40-50$ & 11 & 40.7 & - & - \\
\hline$>50$ & 7 & 25.9 & - & - \\
\hline Total & 23 & 85.18 & 4 & 14.82 \\
\hline
\end{tabular}


Table 2: Year wise distribution of cases

\begin{tabular}{|c|c|c|c|}
\hline Year & No. of autopsies & $\begin{array}{c}\text { Cases with tuberculous } \\
\text { lesions }\end{array}$ & $\%$ \\
\hline 2015 & 289 & 9 & 3.1 \\
\hline 2016 & 283 & 8 & 2.8 \\
\hline 2017 & 229 & 10 & 4.3 \\
\hline Total & 801 & 27 & 3.37 \\
\hline
\end{tabular}

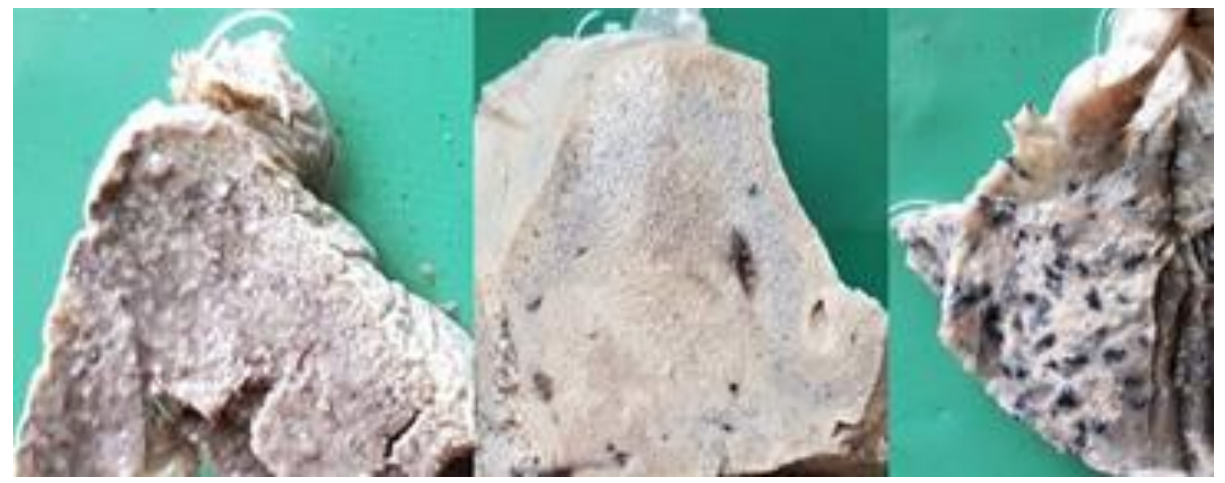

Fig. 1
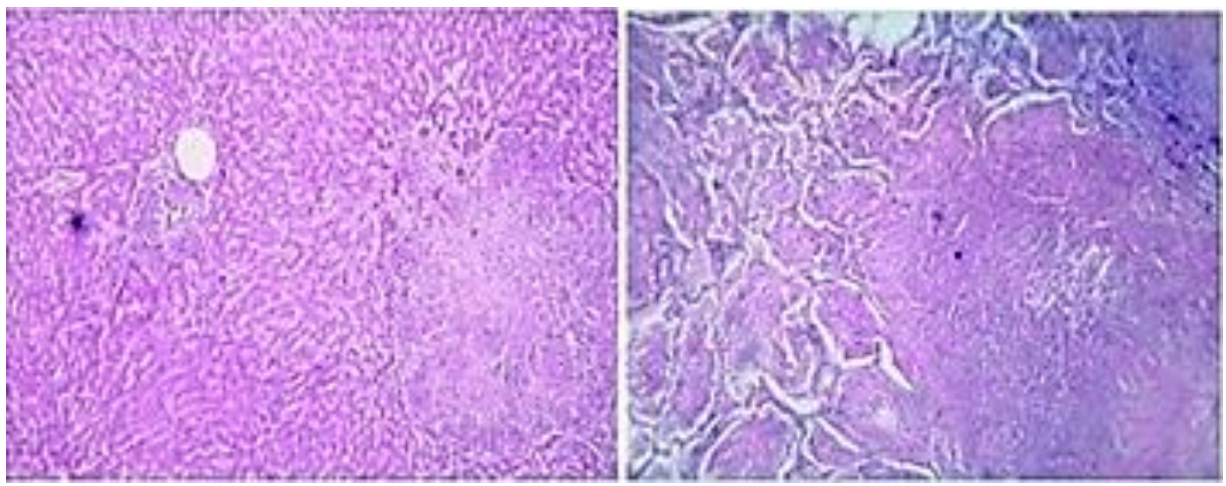

Fig. 2

\section{Discussion}

Our study shows that tuberculosis is commonly seen in autopsies. In this study $3.37 \%$ cases of tuberculosis were diagnosed at forensic autopsies. (Table 2) A study done by Adrion et al., from Italy showed $1.9 \%$ of cases of tuberculosis at autopsies. ${ }^{3}$ Several autopsy studies in India show on an average $28 \%$ tuberculous lesions in autopsy cases. ${ }^{4}$

In our study, tuberculous lesions were seen more in males $(85.18 \%)$ than in females $(14.82 \%)$. (Table.1). In studies by Bavikar et al, Pavic et al., Matthew et al., and Devi et al., also the occurence was similar. ${ }^{4-7}$

Our study shows men in the age group of 40-50 years to be mostly affected whereas other autopsy studies show varied data. In a study by Devi et al., males in $5^{\text {th }}$ decade were commonly affected. In another study by Robert et al., the commonest age group was above 60 years and a study by Sanefuji et al., in Japan showed that men between $70-80$ years to be more commonly affected. ${ }^{8,9}$

Disseminated tuberculosis was seen in 5 out of 27 cases in our study (18.8\%). Other comparative studies by Bavikar et al., Theegarten et al., and Sanefuji et al., showed miliary tuberculosis in $54.1 \%, 14.5 \%$ and $19 \%$ of cases repectively., ${ }^{910}$ Active lesions with dissemination emphasizes the need for increased clinical awareness and efficient screening programmes.

Pulmonary involvement was seen in all cases included in our study. The commonest organ involved was lung followed by spleen and liver in multiple studies. A study by Garg et al., showed lung as the commonest organ involved..$^{11}$ In our study disseminated tuberculosis with involvement of lung, spleen and liver were found in 5 out of 27 cases. In study by Szopinski et al., similar involvement was seen in $47.8 \%$ cases and $33.3 \%$ cases had involvement of these organs in a study by Aaron S Karta et al.. ${ }^{12,13}$

In our study many cases were undiagnosed as tuberculosis in life. Several studies show many cases being diagnosed only at autopsies. ${ }^{11}$ In a study by Hoshino et al., $55.7 \%$ of pulmonary tuberculosis and $21.9 \%$ of miliary tuberculosis were undiagnosed before death. ${ }^{14}$ Similarly, a study by Matthew Bates et al., showed $25.6 \%$ cases to be undiagnosed. 25 out of 33 active tuberculosis i.e., nearly $75 \%$ were unrecognized 
before autopsies in a study by Pavic et al.,., ${ }^{5,6} \mathrm{~A}$ study by Szopinski et al., had $39 \%$ undiagnosed cases. ${ }^{12}$ In nondiagnosed cases, clinical diagnosis were pneumonia, bronchitis, interstitial pneumonia, respiratory failure or lung cancer before autopsy. ${ }^{14}$

In our study, one case was a health care worker with history of fever for one week with sudden collapse and death. The patient had miliary tuberculosis. A study by Garg et al., also had one case of military TB with similar clinical features and death. ${ }^{11}$

In our study active tuberculosis in the form of caseating and non caseating granulomas, pneumonia or disseminated tuberculosis accounted for $88 \%$ cases whereas inactive fibrous tuberculosis confined to the lungs was seen in only $12 \%$ cases. A study by Pavic et al., study showed that $54 \%$ of tuberculosis at autopsy were active cases. ${ }^{5}$ In autopsy study by Devi et al., inactive tuberculosis was more with $65.17 \%$ compared to active lesion which was seen in $34.28 \%$ of cases. In a study by Szopinski et al., active tuberculosis was seen in $7.96 \%$ cases. $^{12}$

Mycobacterium bacilli can survive for years after death of an infected individual. ${ }^{16}$ Cutaneous and respiratory infections from tuberculous tissues in pathology department has been studied in many studies. Autopsy exposure is more infectious than exposure during life. ${ }^{7}$

\section{Conclusion}

Our study demonstrated tuberculosis as a comorbidity finding in $3.37 \%$ of autopsy cases. Active lesions were seen in most of the cases. Increased awareness of the continuous presence of Tuberculosis is needed. Early diagnosis of tuberculosis is important for inhibiting spread of bacteria. Autopsy room may be a place for contact with Mycobacterium tuberculosis and a potential source of risk for health care personnels. Such autopsy findings revealing multi organ involvement by tuberculosis could throw more light on the awareness and effectiveness of anti-tuberculous guidelines.

\section{References}

1. WHO. Global tuberculosis report 2017.:http://www.who.int/tb/publications/global_repor t/2017/en/index.html

2. Lenaerts A, Barry CE, Dartois V. Heterogeneity in tuberculosis pathology, microenvironments and therapeutic responses. Immunological Reviews. 2015;264(1):288-307.

3. Andrion A, Bona R, Mollo F. Active tuberculosis unsuspected until autopsy. Minerva Med 1981;72,7380.
4. Bavikar R, Valand A, Kumar H, Gore C, Iqbal M. Tuberculosis at autopsy in inpatients at a tertiary referral centre in India: a prospective study. Indian Journal of Pathology and Oncology. 2015;2(4):186.

5. Pavić I, Radulović P, Bujas T, Balja MP, Ostojić J, Baličević D. Frequency of tuberculosis at autopsies in a large hospital in Zagreb, Croatia: a 10-year retrospective study. Croatian Medical Journal. 2012;53(1):48-52.

6. Bates M, Mudenda V, Shibemba A, Kaluwaji J, Tembo J, Kabwe M, et al. Burden of tuberculosis at post mortem in inpatients at a tertiary referral centre in subSaharan Africa: a prospective descriptive autopsy study. The Lancet Infectious Diseases. 2015;15(5):544-51.

7. Devi T, Sarangthem B, Keisham S, Devi P, Sangma M. Prevalence of tuberculosis: A study in forensic autopsies. Journal of Medical Society. 2014;28(3):162.

8. Roberts, F. J., M. R. Trueman, G. E. Trueman. Undiagnosed Tuberculosis at Autopsy. Canadian Journal of Public Health / Revue Canadienne De Sante'e Publique 62, no. 6 (1971):496-502.

9. Sanefuji H, Adachi H, Baba K, Oda S, Nakata H, Hayashi M._An autopsy case of miliary tuberculosis and review of autopsy cases in Japan. J UOEH 1984 Mar 1;6(1):75-86.

10. Theegarten D, Kahl B, Ebsen M. Häufigkeit und Morphologie der Tuberkulosebei Obduktionen: Zunahmeaktiver Formen. DMW - Deutsche Medizinische Wochenschrift. 2006;131(24):1371-6.

11. Garg M, Aggarwal AD, Singh S, Kataria SP. Tuberculous lesions at autopsy. J Indian Acad Forensic Med 2011;33:116-9.

12. Szopinski, J., Remiszewski, P., Szymanska, D., \& Rowinska-Zakrzewska, E. (1993). [Tuberculosis found in autopsies done in the Institute of Tuberculosis and Lung Diseases 1972-1991]. Pneumonologia i Alergologia Polska, 61(5-6), 275-279.

13. Karat AS, Omar T, von Gottberg A, Tlali M, Chihota VN, et al. (2016) Autopsy Prevalence of Tuberculosis and Other Potentially Treatable Infections among Adults with Advanced HIV Enrolled in Out-Patient Care in South Africa. PLOS ONE 11(11): e0166158.

14. Hoshino H, Sugawara I, Ohmori M, Wada M. Evaluation of accuracy of clinical diagnosis of TB by annual autopsy report. Kekkaku 2007 Mar;82(3):16571.

15. Flavin RJ, Gibbons N, O’ Briain DS. Mycobacterium tuberculosis at autopsy - exposure and protection: an old adversary revisited. Journal of Clinical Pathology. 2007;60(5):487-491.

16. Gerston KF, Blumberg L, Tshabalala VA, Murray J. Viability of mycobacteria in formalin-fixed lungs. Hum Pathol. 2004;35:571-575.

How to cite this article: Dina MM, Rajesh A, Suresh DJ. Tuberculosis as a co-morbidity finding in medicolegal autopsies. Ind J Pathol Oncol, 2018;5(3):382-384. 